\title{
PALESTRA: \\ Mesa Redonda: currículo, cultura \\ e universidade
}

Cristina Grossi

Dou início ao tempo que me foi reservado para expor minhas idéias, começando com uma citação de Swanwick que acredito, encontrará eco em muitos de vocês.

"Ao visitar uma universidade Canadense, há alguns anos atrás, entrei em uma sala de Análise Musical. Os estudantes estavam examinando uma obra do século XX para clarinete e piano, e acharam que ela tinha 'forma ternária'. Durante a audição, ouvi fragmentos hesitantes de som no registro grave do clarinete que gradualmente foi tomando uma forma firme até tornar-se melodia. Esta melodia foi então sendo ampliada pelo piano através de extensos acordes e oitavas, em forma volumosa em som. Então veio o processo inverso, abrandado e fragmentado. Imaginei que seria possível pensar numa parte intermediária expandida como ' $B$ ' em uma estrutura geral 'ABA', mas ao meu ver parecia mesmo tomar a forma de um arco-íris. Fui então convidado a comentar a peça e mencionei isto. "Puxa", disse um dos estudantes, "era assim que estava acostumado a ouvir música antes de entrar para a universidade." (Swanwick, 1996, p.4) 
A experiência relatada por Swanwick junto aos alunos canadenses de graduação mostra-nos, entre outras coisas, que algo muito sério pode estar acontecendo também nos cursos superiores de música do Brasil. De fato, muitos de nós sentimos, há muito, que algo importante vem sendo desconsiderado, ou negligenciado, ou mesmo excluído em nossos encontros com os estudantes. É no desejo de entender o que se passa, de fazer sempre melhor, de entender a amplitude do universo musical, de rever nossas próprias posições, concepções e práticas que nos professores, temos nos encontramos frequentemente. Temos tido esses encontros no intuito de compartilharmos e refletirmos sobre o assunto.

Aqui estamos, mais uma vez e neste processo, reunidos para tratar de um tema que envolve campos instigantes e complexos como currículo, cultura e universidade. As reflexões que faremos convida-nos a uma atitude interdisciplinar e uma predisposição para o diálogo criativo com a diversidade e as diferenças, sejam elas individuais ou coletivas. Aprendi que entender a música no contexto da cultura pode-nos ajudar a entender não somente diferentes práticas culturais como também algo sobre a nossa própria cultura.

É este campo - o da cultura - que pretendo privilegiar neste artigo. No amplo espectro conceitual, pretendo explorar um pouco aquele que entende cultura como criação, construção e/ou forma de representações simbólicas (Hall, 
1994; Giroux e Simon, 1995; Costa, 1998; Berticelli, 1998; Swanwick, 1999; e outros), que produzem significados, disseminam 'discursos', e através destas, podem tanto construir, fabricar 'identidades' quanto excluir de seus domínios a diversidade das formas de saber. É nesta perspectiva que o currículo e a universidade serão tratados. Antes porém, considero relevante tentarmos entender 0 provável momento em que nos encontramos, especialmente aquele definido pelo professor Boaventura de Souza Santos (em Malerba, 1995; 1995/1999), como o período de 'transição paradigmática'.

A 'transição paradigmática' caracteriza-se por uma ruptura em relação ao modelo de conhecimento desenvolvido pela ciência moderna. Sabe-se que ela excluiu de seus sistemas epistemológicos outras formas de saberes (denominadas de 'vulgar' e 'pouco rigorosa), instituindo assim, um modelo de cientificidade, de conhecimento hegemônico e tecnicista. Outras formas de conhecimento foram relegadas para uma posição de 'vulgaridade' ou de 'ignorância' - entre estes, incluem-se os saberes da cultura popular, a dos indígenas, de pessoas com diferentes orientações sexuais, das mulheres (e entre elas, as feministas), das crianças (meninos e meninas), dos adolescentes, dos negros, dos negros, e das comunidades mais carentes. Santos (em Malerba, 1995. p.2) descreve também este período de transição como aquele em que sabemos mais o que não queremos do 
que aquilo que queremos, onde criticamos muito mais inteligentemente o que "nos tem sido hegemônico e dominante do que configurar aquilo que realmente necessitamos".

Nosso percurso hoje parece ser o de buscarmos, de explorarmos outras possibilidades do 'saber', vislumbrarmos paisagens por tanto tempo desconsideradas, percorrermos muito mais caminhos diferentes do que mover-nos por aqueles que acreditamos já conhecer. Esta atitude ou desejo pelo 'novo' e/ou 'diferente' não parece ser estranho entre nós educadores musicais; vale lembrar, entre outras, nossas aventuras pelos reinos de Orff, Kodály e Suzuky, e nossas incursões pelos idéias de Stravinsky, Cage e Koellreutter. Parece ser nossa trilha, sempre saudável, ir em busca de novas fontes do saber. No entanto, trago esta breve descrição de algumas das idéias de Boaventura, especialmente porque ao lembrar-nos dos 'prejuízos' que advém da atitude de excluir, fala da necessidade da inclusão; aponta para a busca de outros modos de conhecer. Como ele nos lembra, "todas as práticas de conhecimentos correspondem também a práticas sociais" (em Malerba, 1995, p.3). Sabemos que as práticas sociais estão intima e diretamente relacionadas à cultura, sendo a recíproca também verdadeira, ou seja, o conhecimento da cultura dá-se através de um complexo processo que é fundamentalmente social na sua origem.

Cultura, em uma perspectiva relativista, é definida como sendo um terreno real das 
práticas, das representações, línguas e costumes de qualquer sociedade histórica específica. Relaciona-se também, segundo Costa (1998, p.40) às "formas contraditórias de 'senso comum' que se enraizaram na vida popular e ajudaram a molda-las". Esta autora, seguindo os pressupostos de Foucault, defende o conceito de cultura como "um espaço flexível de significação", concebida, "em certo sentido, como construções simbólicas que nos precedem e, como tal, nos instituem e nos ultrapassam" (Idem, p.40). São nos processos de construções simbólicas que surgem as representações, e estas se estabelecem e ganham força através dos discursos. São as representações que instituem os significados "de acordo com critérios de validade e legitimidade estabelecidos segundo relações de poder". Nesta perspectiva, as representações são 'mutantes', 'não fixas', o que significa que não expressam um suposto 'correto', 'verdadeiro', 'melhor' (Idem, p.41).

As formas de representação ganham força através do discurso. Sobre isso, lembro do sociólogo inglês Stuart Hall (1994, p.295) que se refere aos discursos como produtores de conhecimento significativo sobre aquilo que eles falam, pensam ou representam. $E$ "este conhecimento influencia as práticas sociais, e portanto, tem conseqüências e efeitos reais". Discursos não são reduzidos aos interesses de classe, diz ele, mas sempre operam em relação ao poder - "são parte das vias pelas quais o poder circula e é contestado". 
Sabemos que a música emerge sempre de um contexto social e cultural. Na concepção de cultura como representações simbólicas, cabe perfeitamente a noção de música como uma destas formas de representação. Swanwick (1999, p.23) é um dos educadores musicais da atualidade que situa a música neste território. Segundo ele, música é "uma forma de discurso sobre vários níveis metafóricos"; lembra-nos também que todos aqueles envolvidos com a educação deveriam considerar esta premissa. Fala de música não somente como "um modo de pensar, de conhecer", mas também, como forma discursiva, simbólica e expressiva - e é aqui, segundo ele, que reside a principal significação e valor da música. "É um valor compartilhado com outras formas de discurso, pois elas articulam e preenchem os espaços entre diferentes indivíduos e várias culturas". 0 discurso musical, diz Swanwick,

"é inerentemente social, não no sentido determinístico de representar ou 'refletir' a sociedade, mas porque qualquer forma de discurso depende de negociações com sistemas de significados compartilhados... 0 discurso musical pode também ser uma janela através do qual podemos vislumbrar um mundo diferente. Como todas as formas de discurso, música une o espaço entre indivíduos e entre diferentes grupos sociais" (Idem, p.27).

Com os discursos vêm também o poder ou, como diz Costa (1998, p.41), ‘o jogo de 
correlação de forças'. O poder alimenta as representações e encontra voz nos discursos - é algo sempre 'disseminado e circulante'. É através das representações, dos discursos, que o poder tanto estabelece o que é válido e legítimo, quanto institui 'realidades', dizendo o que é certo e errado, o que é normal e o que não é. Assim, como observa Costa (Idem, p.41), nas representações de poder, há uma disputa "por narrar 'o outro' tomando a si próprio como referência, como normal, e o outro como diferente, como exótico". É nessa forma ou o regime de verdades, "que são constituídos os saberes em que fomos ensinados a acolher como verdadeiros, como 'científicos', como universais, e que inundam [nossos] currículos" (Idem, p.43).

Para a elaboração, reformulação, ou mesmo para a análise dos currículos já existentes, as idéias expostas podem contribuir para uma concepção de currículo mais próxima às questões que trago aqui sobre cultura. A primeira pergunta que surge quando o assunto se refere ao currículo é: currículo para quem? Currículo, na visão de Berticelli (1988, p.160), é "o lugar de representação simbólica, transgressão, jogo de poder, lugar de escolhas, inclusões e exclusões, produto de uma lógica explícita muitas vezes e, outras, resultado de uma 'lógica clandestina', que nem sempre é a expressão da vontade de um sujeito, mas imposição do próprio ato discursivo". Costa (1998, p.41) acrescenta que o currículo constitui-se na "arena onde estão em luta visões 
de mundo e onde se produzem, elegem e transmitem representações, narrativas, significados sobre as coisas e seres do mundo". Diz também que "é um texto que pode nos contar muitas histórias", mas no entanto, "temse se constituído em uma prodigiosa maquinaria destinada a excluir" (Idem, p.61). Uma análise de currículo à luz da cultura remete-nos ao fato de que ele é um poderoso instrumento regulador de representações, discursos, inclusões e exclusões, produção e difusão de identidades. Então, identidades são também 'inventadas', 'socialmente construídas', e o acesso a qualquer uma delas é sempre mediado pelos discursos (Costa, 1998, p.50).

A universidade é tida como o local próprio para a produção e promoção de conhecimentos, e entre suas funções estão a investigação científica, o ensino, e a prestação de serviços. No seu estudo sobre a universidade, Santos (1995/1999) fala-nos da 'crise institucional' na qual ela vive atualmente. Por mais paradoxal que possa parecer, diz que a universidade é uma das instituições mais sólidas, que dificilmente muda e que mais resiste e, por isso, só mudará a partir de fora. No entanto, ele como muitos de nós, acreditamos que a universidade é ainda o local propício para criar diferentes lugares epistemológicos e pô-los a dialogar uns com os outros. Os conhecimentos alternativos que foram excluídos pela ciência moderna estão hoje ganhando espaço na universidade. No entanto, em uma análise um pouco mais atenta das propostas curriculares das instituições 
educacionais, incluindo a universidade, encontramos a presença marcante de um discurso que é ainda hegemônico. Como observa Santomé (1995/98, p.161), "as culturas ou vozes dos grupos sociais minoritários e/ou marginalizados que não dispõe, de estruturas importantes de poder costumam ser silenciadas, quando não estereotipadas e deformadas, para anular suas possibilidades de reação".

É comum ouvir hoje em nosso meio universitário que queremos preparar os estudantes para serem cidadãos ativos e críticos, membros solidários e democráticos; queremos também, de acordo com Santomé (1995/98, p.159), que eles "pratiquem e se exercitem em ações capazes de prepará-los adequadamente para viverem e participarem em sua comunidade". Em nosso discurso, parece que já vislumbramos aquilo que queremos e/ou necessitamos. Temos falado muito sobre o que queremos para os estudantes, mas pouco sabemos o que eles 'realmente' querem. Trazendo a experiência vivida por Swanwick com estudantes canadenses, podemos então questionar o seguinte: Como nossos estudantes ouvem e respondem à música antes de ingressar na graduação?; De que universo cultural são eles?; Que tipo de 'saberes' trazem?

Acredito que o que está verdadeiramente ausente em nossos currículos são as vozes e os saberes de nossos estudantes. Exemplos desta situação encontramos frequentemente em nossa vida acadêmica. Continuamos a acreditar que 
somos os únicos responsáveis por definir a melhor metodologia de trabalho, definir os conteúdos e a seqüência em que estes devem ser desenvolvidos. Fazemos isso por acreditarmos que sabemos como 'torná-los musicais', 'prepará-los ou torná-los competentes' para lidar com a música.

Se olharmos atentamente para nossos estudantes de música, veremos que eles já trazem consigo experiências e saberes que frequentemente desconsideramos. Podemos verificar, por exemplo, que alguns deles tocam em bandas de rock e sabem muito sobre o rock; outros improvisam no jazz com muita desenvoltura; um ou outro aprendeu a tocar bateria, ou pandeiro, de forma autodidata; um ou outro toca viola caipira em grupo de violeiros; um ou outro já trabalha em estúdio de gravação; um ou outro que sabe brincar com a voz e, apesar de nunca ter estudado formalmente canto, buscou sempre aprender, observando e conversando com cantores 'da noite'. Há também aqueles que trabalham com crianças no ensino fundamental, e sabem muito sobre o universo infantil. Vale lembrar também que entre nossos estudantes, encontramos indivíduos que além da experiência musical prévia (cada vez mais oriundos da educação informal), vêm também de realidades diferentes das nossas e com saberes muito próprios. Entre eles podem estar negros, de descendência asiática, de diferentes orientação sexual, casados e solteiros, diferentes religiões, homens e mulheres de classes sociais distintas. Então, se 
em nosso discurso falamos em preparar os alunos para intervir na realidade, precisamos ao menos constatar que muitos deles já 'intervém' de fato. Sendo assim, só temos a ganhar ao estabelecer com eles um diálogo de reciprocidade, compartilharmos com eles os nossos saberes e os deles.

Das ciências exatas podemos também trazer um exemplo sobre uma certa 'concepção' de saber. Alguns docentes acreditam que o uso de calculadoras eletrônicas é prejudicial para a aprendizagem da matemática, e no entanto e apesar desta concepção, são os jovens os que mais 'brincam' com os computadores, são eles os 'especialistas' da informática. É comum ouvirmos nos meios de comunicação, que os 'hackers', aqueles piratas eletrônicos que desenvolvem programas para interceptarem mensagens, entrando em sistemas protegidos, são jovens entre 15 e 20 anos.

Parece que na universidade, estamos ainda divididos entre a cultura do professor e a cultura do aluno, sendo que a primeira tende a prevalecer, impondo seu discurso, seu poder, sua visão de mundo, sua visão de música e musicalidade. São os estudantes que entram e saem da universidade, mas com eles vem o dinamismo cultural - com eles temos muito o que aprender. 0 caminho saudável que temos é compartilhar, negociar poderes, dividir responsabilidades, pesquisar com eles. Colaboraremos com eles seja para supervisionar ou orientar os trabalhos que emergem das 
discussões, seja para propor possíveis soluções para os problemas que eles levantam, ou propor caminhos para uma compreensão mais diversificada dos conteúdos eleitos a partir da necessidade deles, seja para propor atividades que possam estimular o pensamento autônomo, reflexivo e criativo dos estudantes, seja enfim, para acompanhar direta ou indiretamente os processos de avaliação.

É relevante lembrar que as idéias sobre cultura e currículo que aqui falei mostram-nos que é com o 'diferente', com o outro, com o aluno, que poderemos compartilhar os saberes $\mathrm{e}$ encontrar horizontes educacionais mais condizentes com uma sociedade mais solidária e humana. É no exercício cotidiano do diálogo construtivo com os estudantes, com a diversidade e as diferenças, que poderemos juntos, quem sabe, vislumbrar a aurora boreal. Nosso tema é música mas é também vida. 0 currículo hoje aponta para a inclusão do outro, e assim, para a diversidade dos saberes e das práticas culturais. Não precisamos ir muito longe para convivermos com a diversidade porque em nossa 'classe', em nosso espaço de trabalho, já encontraremos essa diversidade entre nossos estudantes. Aprenderemos com eles e eles conosco. Acredito que o currículo terá sempre um elemento controlador, por sua própria natureza em estabelecer diretrizes e regular ações; terá sempre uma visão de mundo específica, mas aqui, o caminho aponta para o plural e não para o singular. 


\section{Referências bibliográficas}

BERTICELLI, Ireno A. "Currículo: tendências e filosofia", em $O$ currículo nos limiares do contemporâneo, pp.159-176, Org.: Marisa V. Costa. Rio de Janeiro, DP\&A Editora, 1998.

COSTA, Marisa Vorraber. "Currículo e política cultural", em $O$ currículo nos limiares do contemporâneo, pp.37-68, Org.: Marisa V. Costa. Rio de Janeiro, DP\&A Editora, 1998.

DEMO, Pedro. Pesquisa - princípio científico e educativo. São Paulo, Cortez Editora, 1996. GIROUX, Henry A. \& SIMON, Roger. "Cultura popular e pedagogia crítica: a vida cotidiana como base para o conhecimento curricular", em Currículo, cultura e sociedade, pp.93-124, Org.: Antonio F. Moreira \& Tomaz T. Silva, São Paulo,

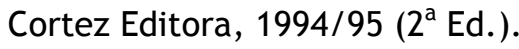

FAZENDA, I. C. A. Integração e interdisciplinaridade no ensino brasileiro. São Paulo, Edições Loyola, 1993.

GROSSI, Cristina D. S. Assessing musical listening: musical perspectives of tertiary students and contemporary Brazilian composers. Tese de PhD, University of London, Institute of Education, 1999.

HALL, Stuart. "The West and the Rest: discourse and power", in Formations of modernity, pp.275-320, Edited by Hall, Stuart \& Gieben, Bram. Cambridge, Polity Press in association with The Open University, 1994. 
JARY, David \& JARY, Julia. Collins dictionary of sociology. Glasgow, Harper Collins Publishers, 1991/95 (2 Ed.).

MALERBA, Jurandir. Entrevista com Prof.

Boaventura de Souza Santos. Coimbra, material não publicado, 1995 (12 páginas).

SANTOMÉ, Jurjo Torres. "As culturas negadas e silenciadas no currículo", em Alienígenas na sala de aula, pp.159-177. Org: Silva, Tomaz T. Petrópolis, Editora Vozes, 1995/98 (2 Ed.).

SANTOS, Boaventura de Souza. "Pela mão de Alice - o social e o político na pós-modernidade. São Paulo, Cortez Editora, 1995/99 (6 ${ }^{\mathrm{a}}$ Ed.).

STOREY, John. An introductory guide to cultural theory and popular culture. New York and London, Harvester Wheatsheaf, 1993.

SWANWICK, Keith. "Teaching music musically", em Kodály envoy - quarterly of the organization of American Kodály educators, Vol.22, No.3, pp.4-9, 1996.

SWANWICK, Keith. Teaching music musically. London and New York, Routledge, 1999. 